\title{
Clinical and biochemical observations on three cases of hypoxanthine-guanine phosphoribosyltransferase deficiency
}

\author{
D. N. BUNN, I. K. MOSS, A. NICHOLLS, J. T. SCOTT, M. L. SNAITH, AND \\ M. R. WATSON \\ From the Kennedy Institute of Rheumatology and North-East London Polytechnic, London
}

\begin{abstract}
Bunn, D. N., Moss, I. K., Nicholls, A., Scott, J. T., Snaith, M. L., and Watson, M. R. (1975). Annals of the RheumaticDiseases, 34, 249-255. Clinical and biochemical observations on three cases of hypoxanthine-guanine phosphoribosyltransferase deficiency. Clinical and enzymatic studies on two brothers with severe deficiencies of erythrocyte hypoxanthineguanine phosphoribosyltransferase (HGPRTase) are described, and are compared with similar studies of a classical case of the Lesch-Nyhan syndrome from another family. The two brothers have no neurological abnormalities, only traces of erythrocyte HGPRTase, erythrocyte adenine phosphoribosyltransferase activities approaching the high levels found in the Lesch-Nyhan patient, and similarly raised plasma and urinary concentrations of uric acid. Despite these strong biochemical similarities between the three patients, there were wide differences in the clinical case histories. In both families the enzyme deficiency appeared to be inherited as an X-linked character through asymptomatic carrier females. The relationship of HGPRTase deficiencies to the Lesch-Nyhan syndrome is discussed.

Some observations relating to techniques are reported. Cellulose acetate has been found to give much better separations of labelled reaction products in low-level phosphoribosyltransferase assays than filter paper, when used as a supporting medium for electrophoresis. The analysis of hair follicles gives indications of individuals heterozygous for the enzyme deficiency, but the proportion of enzyme-deficient follicles was very small, and the test needs support from studies of other cell types. Using haemolysates, there were signs of a slow indirect conversion of hypoxanthine to inosinic acid, via inosine. Inosine appears to be labelled by a ribosyl-transfer reaction.
\end{abstract}

In 1967 it was reported (Seegmiller, Rosenbloom, and Kelley, 1967) that patients with the Lesch-Nyhan syndrome of involuntary movements, mental deficiency, self-mutilation, and overproduction of urate were deficient in erythrocyte hypoxanthine-guanine phosphoribosyltransferase (HGPRTase). Subsequently, partial HGPRTase deficiency was reported in a number of patients with overproduction gout without neurological disease (Kelley, Rosenbloom, Henderson, and Seegmiller, 1967). It therefore appeared initially that complete deficiency of HGPRTase was associated with the Lesch-Nyhan syndrome and that partial deficiency resulted in overproduction gout without neurological abnormality; but a number of different combinations of enzyme deficiency in erythrocytes and other tissues, hyperuricaemia, renal disease, and neurological conditions have since been described. Cases of deficiency are comparatively rare; for example, in a previous study from this unit (Eyre, Davison, and Scott, 1971) none were found among 37 subjects with gout. According to Yü, Balis, Krenitsky, Dancis, Silvers, Elion, and Gutman (1972) and Sperling, Frank, Ophir, Liberman, Adam, and De Vries (1970), the incidence of partial HGPRTase in the gouty population is less than $2 \%$. Of this group, about $10 \%$ have neurological manifestations, including mental retardation, mild spastic quadriplegia, dysarthria, cerebellar ataxia, and seizures (Wyngaarden, 1974). The present paper describes comparative clinical and biochemical studies of three cases of HGPRTase deficiency, one being a classical case of the Lesch-Nyhan syndrome (M.B.), the other two 
being brothers from a different family, one with gouty arthritis (G.H.), the other asymptomatic (K.H.), but both with very severe deficiencies approaching those found in most cases of the LeschNyhan syndrome.

The Lesch-Nyhan syndrome is a familial disease which is inherited in a way suggesting an X-linked character (Nyhan, Pesek, Sweetman, Carpenter, and Carter, 1967). Enzyme levels in erythrocytes from other members of the two families were also studied in a search for affected individuals. Gartler, Scott, Goldstein, Campbell, and Sparkes (1971) have reported a convenient method for detecting heterozygotes by enzyme assays on hair follicles; this method was also used to search for heterozygotes in the two families.

\section{Methods}

ENZYME ASSAYS

(i) HGPRTase and adenine phosphoribosyltransferase (APRTase) in erythrocytes

These activities were assayed in dialysed haemolysates according to Kelley and others (1967). The substrates used were $8-\mathrm{C}-14$ hypoxanthine $(0.66 \mathrm{mmol} / \mathrm{l}, 5.0 \mathrm{mCi} / \mathrm{mmol})$ or $8-\mathrm{C}-14$ adenine $(0.66 \mathrm{mmol} / 1,4.5 \mathrm{mCi} / \mathrm{mmol})$ (obtained from Radiochemical Centre, Amersham, Bucks.). Reaction products were separated by high voltage electrophoresis on filter paper, or by ascending chromatography in $10 \%(\mathrm{w} / \mathrm{v}) \mathrm{Na}_{2} \mathrm{HPO}_{4} .12 \mathrm{H}_{2} \mathrm{O}$. The nucleotide product was located in ultraviolet light, and then the strips were scanned in a Packard Model 7201 chromatogram scanner. The strip was then dissected into $1 \mathrm{~cm}$ segments transverse to the direction of migration and assayed for radioactivity using a Packard model 3320 liquid scintillation spectrometer. The scintillation fluid contained $0.5 \%(w / v)$ PPO (2,5 diphenyloxazole) and $0.05 \%(w / v)$ POPOP (1,4 bis 2-(5-phenyloxazolyl)benzene) in toluene. For the determination of low levels of enzyme activity the assay was modified as follows. The erythrocyte protein used per incubation was increased tenfold to about $3 \mathrm{mg}$, and a higher specific activity substrate (8-C-14-hypoxanthine, $51 \cdot 2$ $\mathrm{mCi} / \mathrm{mmol}$, obtained from N.E.N. Chemicals, Mannheim, Germany) was used. The reaction products were separated by high voltage electrophoresis on paper or on cellulose acetate membranes (Oxoid or Shandon Cellogram strip), the latter being found to give far better separation. Blanks were prepared by omitting phosphoribosylpyrophosphate (PRPP) from the reaction mixtures. On electrophoresis these blanks showed migration of isotope to the position expected for inosinic acid (inosine 5'-monophosphate, IMP), usually amounting to $0.05-0.10 \%$ of total radioactivity. Of this, about $0.05 \%$ was present as impurity in the original isotope.

\section{(ii) HGPRTase and APRTase in hair follicles}

These were assayed by the method of Gartler and others (1971). Approximately 20 follicles were plucked from the scalp of each subject and immediately placed in a buffer solution $(30 \mu \mathrm{l})$ and frozen. The composition of this buffer solution was $0.25 \mathrm{~mol} / 1$ tris $-\mathrm{HCl}, \mathrm{pH} 7.4 ; 0.02 \mathrm{mmol} / 1$ $\mathrm{MgCl}_{2} ; 0.005 \mathrm{mg} / \mathrm{ml}$ bovine serum albumin; $1.6 \mathrm{mg} / \mathrm{ml}$ benzyl penicillin, and $1.6 \mathrm{mg} / \mathrm{ml}$ streptomycin base. After freezing and thawing three times the samples were transferred to a water bath at $37^{\circ} \mathrm{C}$ and the reaction started by the addition of substrate. The substrate solution contained $0.625 \mathrm{mmol} / 12-\mathrm{H}^{3}$-adenine of specific activity $500 \mathrm{mCi} / \mathrm{\omega}$ mmol (5 $\mu \mathrm{l}) ; 1.91 \mathrm{mmol} / 1$ 8-C-14 hypoxanthine $(5 \mu \mathrm{l})$, and $0.6 \%$ (w/v) dimagnesium PRPP $10 \mu \mathrm{l}$ (P-L Biochemicals, Inc., Milwaukee, Wisconsin). The reaction was stopped after $1 \mathrm{~h}$ by the addition of $0 \cdot 2 \mathrm{~mol} / 1 \mathrm{EDTA}(10 \mu \mathrm{l})$. Blanks $\frac{\bar{\sigma}}{\sigma}$ were prepared without the addition of PRPP. The reaction $\overline{\bar{\omega}}$ products were separated by ascending chromatography on $\underset{\nabla}{\overparen{D}}$ polyethyleneimine cellulose thin layer plates (Machery- 2 Nagel PEI Cell 300 UV254) with water as solvent. The \& chromatograms were scanned in a Packard model $7201 \vec{\circ}$ chromatogram scanner, the products transferred to scin-? tillation fluid, and counted for ${ }^{3} \mathrm{H}$ and ${ }^{14} \mathrm{C}$.

(iii) Purine nucleoside phosphorylase (PNPase)

This was assayed in dialysed haemolysates by the following spectrophotometric method. A medium containing $2 \cdot 70^{\circ}$ $\mathrm{mmol} / \mathrm{l}$ inosine, $35 \mathrm{mmol} / \mathrm{l}$ phosphate buffer (pH 7.4), and + 0.036 units of xanthine oxidase (Koch-Light Chemicals, $\omega$ Bucks). was incubated with $100-250 \mu \mathrm{g}$ of haemolysate protein. The rate of increase in optical density at $290 \mathrm{~nm}_{0}^{6}$ was observed in a Unicam S.P. 500 spectrophotometer. The rate of increase was shown to be proportional to the PNPase concentration, over the range $100-250 \mu \mathrm{g}$ erythrocyte protein.

PLASMA AND URINARY URIC ACID, XANTHINE, AND $\vec{\vartheta}$ HYPOXANTHINE

Plasma and urinary uric acid was measured by an en $\square$ matic spectrophotometric method (Liddle, Seegmiller, a Laster, 1959). Urinary hypoxanthine and xanthine we measured by an enzymatic conversion to uric acid (Klinenberg, Goldfinger, Bradley, and Seegmiller, 1967).응 All plasma and urinary estimations on the subjects undero investigation were performed while they were receiving $\mathrm{a}=\overrightarrow{\bar{O}}$ low-purine diet.

\section{Case histories}

M.B. was born on August 27, 1955 after normal pregnancy and delivery (birthweight $3 \mathrm{~kg}$ ). At the age of 9 months he was unable to sit, had poor head control, and a tendency to opisthotonos with exaggerated limb reflexes. By 2 years. he was just able to sit with help and had developed involuntary jerking movements of his arms and legs. $\mathrm{He}^{3}$ started biting his hands and lips and at this time orangeo crystals were noted around the perineum. By the time he was 5 years old, his deciduous teeth had to be removed be-o cause of lip and tongue biting. He then started to have attacks of screaming, shouting, and spitting, and by the age of 9 years he was experiencing violent movements in all limbs associated with continued attempts at self injury including eye-gouging.

In 1967 , at the age of 11 , bilateral stereotactic thalomotomy was performed with only transient improvement in his involuntary movements. However, in the last 5 years his general condition has remained much the same indeed he now seems if anything to be less aggressive and is able to hold a simple conversation, though with pro-nounced dysarthria. There appears to be some periodicity here, episodes of increased motor activity coinciding with? crystalluria, according to his parents, although it has nob yet been possible to study this phenomenon objectively. 
Table I Erythrocyte enzyme activities and data on purine catabolism

\begin{tabular}{|c|c|c|c|c|c|c|}
\hline \multirow{2}{*}{ Subjects } & \multicolumn{3}{|c|}{ Erythrocyte enzymes (nmol product/mg protein per $h$ ) } & \multirow{2}{*}{$\begin{array}{l}\text { Plasma uric } \\
\text { acid } \\
(\mathrm{mg} / 100 \mathrm{ml})\end{array}$} & \multirow{2}{*}{$\begin{array}{l}\text { Urinary } \\
\text { uric acid } \\
(m g / 24 h)\end{array}$} & \multirow{2}{*}{$\begin{array}{l}\text { Urinary xanthine } \\
\text { +hypoxanthine } \\
(\mathrm{mg} / 24 \mathrm{~h})\end{array}$} \\
\hline & HGPRTase & APRTase & PNPase & & & \\
\hline M.B. & $0.05,0.05,0.08^{*}$ & $79 \cdot 6,71 \cdot 6^{*}$ & 1910 & $10 \cdot 6$ & 850 & - \\
\hline $\begin{array}{l}\text { N.B. (mother) } \\
\text { Other members }\end{array}$ & $\begin{array}{r}106 \cdot 7 \\
99 \cdot 2 \pm 20 \cdot 3(17)\end{array}$ & $\begin{array}{l}14 \cdot 5 \\
11 \cdot 3 \pm 2 \cdot 9(5)\end{array}$ & $\overline{17} 30 \pm 364(3)$ & $\begin{array}{l}4 \cdot 66 \\
4 \cdot 67\end{array} 00 \cdot 83(11)$ & & $\bar{Z}$ \\
\hline of family $B \dagger$ & & & & & & \\
\hline $\begin{array}{l}\text { G.H. } \\
\text { K.H. }\end{array}$ & $\begin{array}{l}0.05,0.05,0.06^{*} \\
0.05,0.05,0.18^{*}\end{array}$ & $\begin{array}{l}56 \cdot 7,81 \cdot 6^{*} \\
67 \cdot 7,60 \cdot 1^{*}\end{array}$ & $\begin{array}{l}1340 \\
1420\end{array}$ & $\begin{array}{l}10 \cdot 8 \\
10 \cdot 5\end{array}$ & $\begin{array}{l}1642 \\
1445\end{array}$ & $\begin{array}{l}63 \\
90\end{array}$ \\
\hline D.H. (mother) & 79.9 & $15 \cdot 5$ & 1260 & $7 \cdot 10$ & - & - \\
\hline P.H. (sister) & $58 \cdot 1$ & $17 \cdot 9$ & 1180 & $4 \cdot 15$ & - & 一 \\
\hline $\begin{array}{l}\text { Other members } \\
\text { of family } \mathrm{H} \dagger\end{array}$ & $99 \cdot 7 \pm 11 \cdot 5(8)$ & $14 \cdot 7 \pm 2 \cdot 2$ & $1237 \pm 40(3)$ & $5 \cdot 45 \pm 2 \cdot 05(11)$ & - & - \\
\hline Normal values $\dagger$ & $103 \pm 14 \cdot 0(18)$ & $12 \cdot 7 \pm 3 \cdot 0(11)$ & $1247 \pm 197(14)$ & - & - & - \\
\hline
\end{tabular}

* Duplicate or triplicate determinations; different freshly prepared haemolysates.

$\dagger$ Mean \pm standard deviation; number of estimations in parentheses.

Conversion: traditional to SI units-Plasma uric acid: $1 \mathrm{mg} / 100 \mathrm{ml} \simeq 0.0595 \mathrm{mmol} / 1$ Urinary uric acid: $1 \mathrm{mg} / 24 \mathrm{~h} \simeq 0.00595 \mathrm{mmol} / 24 \mathrm{~h}$

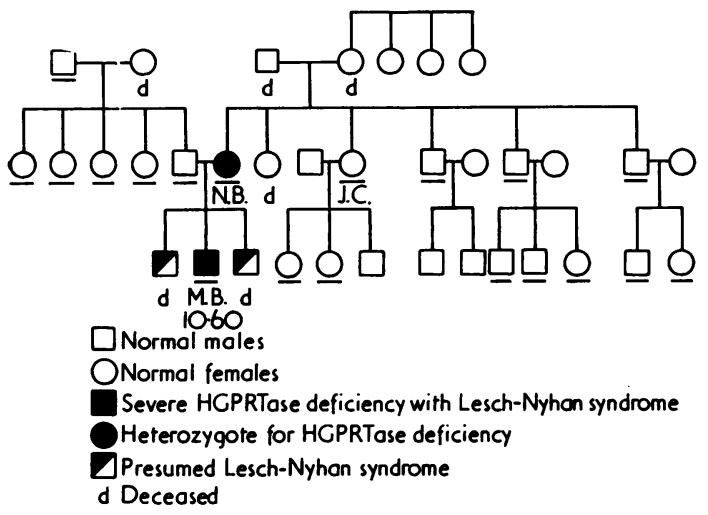

FIG. 1 Family tree (family B). Only the individuals underlined were tested. Initials are inserted to allow identification with text and tables. Figure indicates plasma uric acid value for hyperuricaemic individual

On examination he was a thin edentulous child, friendly, and able to take part in a simple conversation. Widespread athetotic movements of his limbs and face were present.

The values for plasma and urinary uric acid are given in Table I. Creatinine clearance was $39 \mathrm{ml} / \mathrm{min}$. EEG showed irregular slow activity from all areas. IQ was 57 .

Both parents are well and there is no family history of gout or consanguinity. M.B. was the second in a family of three boys (Fig. 1). His elder brother had died in 1957 at the age of 5 years having shown abnormal movements, mental retardation, and self-mutilation. His kidneys were said to be 'gritty' at autopsy but no other details were available. His younger brother had died when a year old, also in 1957. He was also physically and mentally retarded. It seems highly probable that the elder brother and possibly the younger brother were cases of the Lesch-Nyhan syndrome.

G.H. was born in 1947. He was seen initially in 1969 with a 3-year history of recurrent painful swelling of the third right metacarpophalangeal joint with subsequent pain and swelling of both knees. He was found to be hyperuricaemic and sodium urate crystals were shown in synovial fluid. On examination he was overweight and seemed dull. Physical examination was normal: his manner of speaking was a little slurred but there was no definite neurological abnormality. Values for plasma and urinary uric acid are given in Table I. Blood urea was $25 \mathrm{mg} / 100 \mathrm{ml} \mathrm{(4.1} \mathrm{mmol} /$ 1). Creatinine clearance $130 \mathrm{ml} / \mathrm{min}$, intravenous pyelogram normal. IQ was 85 , psychological grading being expressed as 'dull normal'.

K.H., the brother of G.H., was born in 1958. Because of this relationship, plasma uric acid was estimated at the age of 11 years and was found to be raised. He admitted to no symptoms and was making satisfactory progress at school. On examination he was a rather chubby prepubertal boy with no neurological or other abnormalities. EEG was within normal limits. IQ was 91, psychological grading being 'average intelligence'. Plasma and urinary uric acid levels are given in Table I. Blood urea was $30 \mathrm{mg} / 100 \mathrm{ml}$ (5 mmol/1), creatinine clearance $105 \mathrm{ml} / \mathrm{min}$, intravenous pyelogram normal. Both parents are alive and well, and there is no family history of gout or consanguinity. The family tree is shown in Fig. 2.

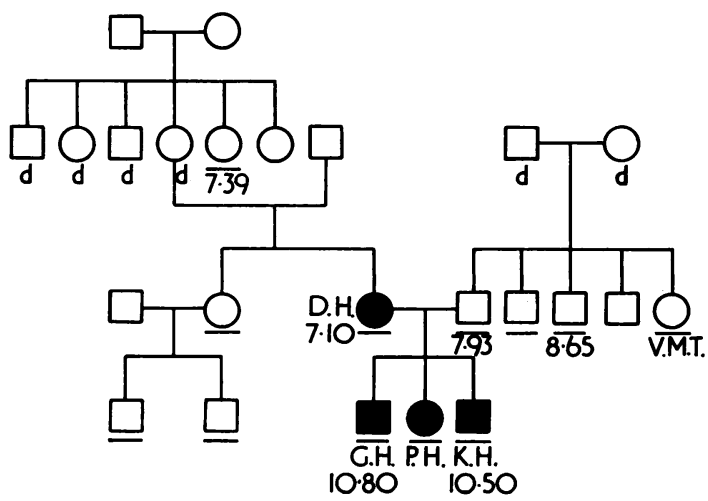

FIG. 2 Family tree (family $H$ ). Key as in Fig. 1, but there are no cases of the Lesch-Nyhan syndrome. Numbers indicate plasma uric acid values from hyperuricaemic relatives 
Table II Response to allopurinol in G. H. and $K . H$.

\begin{tabular}{|c|c|c|c|c|}
\hline & \multicolumn{2}{|l|}{ G.H. } & \multicolumn{2}{|l|}{ K.H. } \\
\hline & Untreated & $\begin{array}{l}\text { On allopurinol } \\
(800 \mathrm{mg} \text { daily })\end{array}$ & Untreated & $\begin{array}{l}\text { On allopurinol } \\
\text { (800 mg daily) }\end{array}$ \\
\hline Mean plasma uric acid $(\mathrm{mg} / 100 \mathrm{ml})$ & $10 \cdot 8$ & $3 \cdot 3$ & $10 \cdot 5$ & $3 \cdot 1$ \\
\hline Mean urinary uric acid (mg/24 h) & 1642 & 272 & 1445 & 140 \\
\hline Mean urinary xanthine + hypoxanthine $(\mathrm{mg} / 24 \mathrm{~h})$ & 63 & 1547 & 110 & 1350 \\
\hline Mean total purine $(\mathrm{mg} / 24 \mathrm{~h})$ & 1705 & 1819 & 1555 & 1490 \\
\hline
\end{tabular}

G.H. and K.H. were both treated with allopurinol and the results are shown in Table II. Allopurinol produced a striking fall in plasma and urinary levels of uric acid, with a corresponding rise in urinary levels of xanthine and hypoxanthine, so that total purine excretion remained unchanged.

\section{Erythrocyte enzymes}

Erythrocyte enzyme activities for the patients and members of their families are shown in Table I. Only three individuals (M.B., K.H., and G.H.) had severe deficiencies. The values for three female relatives of the affected individuals presumed (from hair follicle assays described below) to be heterozygous for HGPRTase deficiency are also shown in Table I; these values are not included in the calculations of the average HGPRTase values for the other members of the families. The mother of M.B. (N.B.) had normal erythrocyte HGPRTase. The mother of the HGPRTasedeficient individuals in family $H$ (D.H.) had a low level of the enzyme which was nevertheless just within the normal range, while the sister (P.H.) had only $58 \%$ normal activity. In family $\mathrm{H}$ there was another partial deficiency, only $50 \%$ activity being found in V.M.T., who was not a blood relative of D.H. This does not relate to the normal pattern of inheritance of HGPRTase deficiency (Fig. 2). Only the individuals with severe HGPRTase deficiencies showed raised erythrocyte APRTase levels; those for all other subjects being within the normal range.

The values given in Table I refer to results from fresh haemolysates. HGPRTase activities for M.B. and G.H. were consistently extremely low, those for K.H. slightly higher, though still showing severe deficiency. After storage of reaction mixtures at $-20^{\circ} \mathrm{C}$ for about 3 months, however, a difference was found between subjects from the two families. With M.B. results after storage remained unchanged, whereas in the cases of G.H. and K.H., the peak for IMP was now more strongly labelled, corresponding to activities of 1.21 and 0.62 units of HGPRTase activity, respectively. This difference is unexplained, although it is notable that in the case of M.B. the inosine peak was also missing (see discussion below on the indirect labelling of IMP). Cellulose acetate was found to possess considerable advantages over filter paper as a supporting medium for the electrophoretic separation of the reaction products of HGPRTase assays, particularly when comparatively large amounts of haemoglobin were present, as in the determination of low enzyme activities. Under these conditions the quality of separations on filter

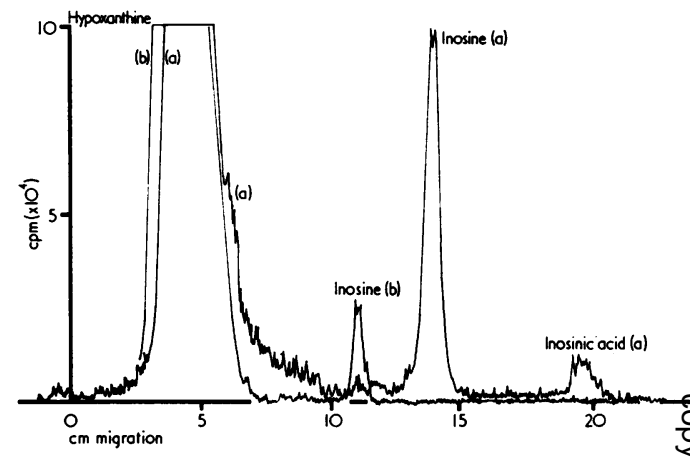

FIG. 3 Traces from the radiochromatogram scanner two separations of reaction products of erythrocy HGPRTase assay on G.H. These are the stored reaction mixtures referred to in the text, showing labelling of IMP in the full reaction mixture $(a)$, but not in the control $(b)$ (no PRPP). The mixtures were separated at $100 \mathrm{v} / \mathrm{cm}$ on $\overrightarrow{\vec{B}}$ cellulose acetate in $0.5 \mathrm{~mol} / \mathrm{l}$ borate, $\mathrm{pH} 9.0$, for $20 \mathrm{~min}$. The 3 strips were scanned at a speed of $1 \mathrm{~cm} / \mathrm{s}$, at a full scale deflection of $10^{4} \mathrm{cpm}$, ratemeter time constant $10 \mathrm{~s}$, slit width $1 \mathrm{~mm}$

paper was variable, and sometimes diffuse zones were obtained. On cellulose acetate the zones remained sharp, $\frac{5}{3}$ and it was much easier to estimate very small quantities of labelled IMP. Tracings from two cellulose acetate separations are shown in Fig. 3.

In most reaction mixtures a third labelled compound 0 was also present, with an electrophoretic mobility between hypoxanthine and IMP (Fig. 3). It was probably inosine $\frac{D}{0}$ because it was found to co-electrophorese with tritiated inosine. Under standard reaction conditions the labelling $\tilde{N}$ of inosine was very weak, but in reaction mixtures to which larger amounts of haemolysate were added, as in the 0 determination of very low HGPRTase activities, the labelling was more pronounced, usually amounting to about $7 \%$ of the total counts. However, this labelling was not consistent, and sometimes it did not appear at all. Labelling of inosine appeared to be stimulated by PRPP (Fig. 3), and addition of $0.6 \mathrm{mmol} / \mathrm{l}$ unlabelled inosine to the reaction mixture increased the labelling to about $20 \%$ 뭉 of the total counts present. This effect of unlabelled inosine $\frac{P}{\mathrm{D}}$ occurred whether or not PRPP was present. The addition $\stackrel{\odot}{\square}$ of $0.6 \mathrm{mmol} / \mathrm{l}$ inosine to a reaction mixture from G.H. also $\stackrel{\mathbb{Q}}{\Omega}$ doubled the labelling of IMP, from $0.08 \%$ to $0.16 \%$ of the 
total counts. This may indicate a very slow conversion of hypoxanthine to IMP through inosine, catalysed by PNPase and inosine kinase. Tritiated IMP was not converted to inosine in our reaction mixtures.

PNPase was initially determined in 14 haemolysates from healthy volunteers, and in 20 haemolysates from gouty patients. The mean values were $1247 \mathrm{nmol}$ uric acid formed per mg erythrocyte protein per $h$, with an SD of 197 for the controls, and $1625 \mathrm{nmol}$ with an SD of 460 from the gouty patients. Values for the subjects under study are shown in Table I. Those from G.H. and K.H. were within the normal range, while the value from M.B. was high but within the gouty range.

\section{Enzyme levels in hair follicles, and detection of heterozygotes}

HGPRTase activities for hair follicles taken from the three enzyme-deficient patients and some suspected heterozygotes are listed in Table III. The APRTase activities act as an internal standard of follicle size, serving to distinguish HGPRTase-deficient follicles from very small follicles, or from follicles damaged during collection (Gartler and others, 1971). The HGPRTase/APRTase ratio is used to pick out results indicating HGPRTasedeficient follicles. Because of the low activity of many follicles, it was decided to select first those with APRTase activities greater than 81 pmol of AMP formed per hour, and where the HGPRTase activity was within one standard deviation of the blank value. It was therefore almost certain that the APRTase 'activities' recorded for these follicles had a component of real APRTase activity, apart from the contribution of the blank. Any of these follicles could have been HGPRTase-deficient, and those values are in italics in Table III. Of this group, the follicles with APRTase activities above 130 pmol of AMP formed per hour (corresponding to HGPRTase/APRTase ratio, after subtraction of blanks, of less than $0 \cdot 1$ ) are in bold type to identify them positively as HGPRTase-deficient. Follicles with ratios below $0 \cdot 1$ are not found in normal subjects (Gartler and others, 1971), and three individuals are therefore identified as heterozygotes for HGPRTase-deficiency, on the basis of the presence of one or two HGPRTasedeficient follicles. They are indicated in the family trees (Figs 1 and 2) and consist of the mother of M.B., and the mother and sister of G.H. and K.H. As already mentioned, the erythrocyte HGPRTase activity of P.H. is below the normal range of activities.

\section{Discussion}

The exact relationship of erythrocyte HGPRTase deficiencies to the Lesch-Nyhan syndrome remains uncertain. A notable feature of the majority of these patients is that they show a virtual absence of erythrocyte HGPRTase, whereas patients with a 'partial' rather than a complete deficiency tend to escape the devastating neurological and behavioural features of the full enzyme defect.

HGPRTase activity in erythrocytes from K.H. and G.H., if present, was small, and certainly within the range of values where neurological features are common. Our results may be added to a growing volume of documentation showing some lack of correlation between the clinical severity of the disease

Table III Phosphoribosyltransferase activities from hair follicles

\begin{tabular}{|c|c|c|c|c|c|c|c|c|c|c|c|c|c|c|}
\hline \multirow[t]{2}{*}{ Subject } & \multicolumn{2}{|c|}{ M.B. } & \multicolumn{2}{|l|}{$N . B}$. & \multicolumn{2}{|l|}{ J.C. } & \multicolumn{2}{|c|}{ G.H. } & \multicolumn{2}{|c|}{ K.H. } & \multicolumn{2}{|l|}{ D.H. } & \multicolumn{2}{|l|}{ P.H. } \\
\hline & $A$ & $H$ & $A$ & $\boldsymbol{H}$ & $A$ & $\boldsymbol{H}$ & $A$ & $\boldsymbol{H}$ & A & $\boldsymbol{H}$ & $A$ & $H$ & $\boldsymbol{A}$ & $\boldsymbol{H}$ \\
\hline $\begin{array}{c}\text { Follicle r } \\
1 \\
2 \\
3 \\
4 \\
5 \\
6 \\
7 \\
8 \\
9 \\
10 \\
11 \\
12 \\
13 \\
14 \\
15 \\
16 \\
17 \\
18 \\
19 \\
20 \\
21 \\
22 \\
23 \\
24\end{array}$ & $\begin{array}{l}66 \\
95 \\
64 \\
80 \\
46 \\
49 \\
40 \\
54 \\
53\end{array}$ & $\begin{array}{l}45 \\
57 \\
50 \\
51 \\
57 \\
46 \\
33 \\
44 \\
42\end{array}$ & $\begin{array}{r}400 \\
346 \\
101 \\
36 \\
1239 \\
161 \\
910 \\
97 \\
79 \\
107 \\
322 \\
68 \\
258 \\
796 \\
742 \\
50\end{array}$ & $\begin{array}{r}73 \\
41 \\
119 \\
70 \\
696 \\
155 \\
697 \\
82 \\
56 \\
50 \\
226 \\
81 \\
84 \\
383 \\
137 \\
52\end{array}$ & $\begin{array}{r}197 \\
64 \\
342 \\
61 \\
141 \\
102 \\
54 \\
62 \\
299 \\
178 \\
92 \\
70 \\
85 \\
75 \\
81 \\
104 \\
107 \\
85 \\
86\end{array}$ & $\begin{array}{r}263 \\
111 \\
363 \\
119 \\
225 \\
224 \\
107 \\
92 \\
374 \\
273 \\
93 \\
96 \\
79 \\
87 \\
64 \\
89 \\
81 \\
80 \\
83\end{array}$ & $\begin{array}{r}106 \\
244 \\
71 \\
306 \\
114 \\
132 \\
337 \\
107 \\
112 \\
95\end{array}$ & $\begin{array}{r}69 \\
106 \\
66 \\
105 \\
51 \\
160 \\
149 \\
154 \\
136 \\
136\end{array}$ & $\begin{array}{r}46 \\
40 \\
293 \\
72 \\
93 \\
214 \\
311 \\
57 \\
82 \\
203 \\
467 \\
63 \\
47 \\
157 \\
529 \\
209 \\
60\end{array}$ & $\begin{array}{l}44 \\
52 \\
42 \\
52 \\
61 \\
55 \\
63 \\
58 \\
61 \\
59 \\
51 \\
62 \\
50 \\
41 \\
53 \\
43 \\
60\end{array}$ & $\begin{array}{r}112 \\
42 \\
304 \\
49 \\
44 \\
1423 \\
1767 \\
34 \\
31 \\
38 \\
48 \\
49 \\
41 \\
48 \\
61 \\
56 \\
55 \\
126 \\
46 \\
51 \\
70\end{array}$ & $\begin{array}{r}84 \\
92 \\
116 \\
50 \\
62 \\
56 \\
715 \\
37 \\
57 \\
38 \\
49 \\
62 \\
43 \\
60 \\
95 \\
48 \\
78 \\
54 \\
45 \\
60 \\
132\end{array}$ & $\begin{array}{r}48 \\
157 \\
38 \\
576 \\
50 \\
726 \\
1465 \\
175 \\
40 \\
803 \\
41 \\
401 \\
59 \\
54 \\
66 \\
39 \\
97 \\
260 \\
184 \\
44 \\
276 \\
40 \\
396 \\
43\end{array}$ & $\begin{array}{r}78 \\
322 \\
63 \\
477 \\
159 \\
530 \\
853 \\
251 \\
60 \\
590 \\
67 \\
84 \\
66 \\
85 \\
71 \\
54 \\
67 \\
58 \\
143 \\
52 \\
126 \\
52 \\
60 \\
48\end{array}$ \\
\hline
\end{tabular}

Activities in bold type identify definite mutant follicles; activities in italics indicate possible mutation (see text).

$A=A P R T a s e$ activity, pmol AMP formed/h per follicle; $H=H G P R T a s e$ activity, pmol IMP formed/h per follicle.

Blank values not subtracted; $A=47 \cdot 6 \pm 9 \cdot 6$ (4); $H=50 \cdot 6 \pm 8 \cdot 3$ (4). 
and enzyme activity in erythrocytes. Sorensen (1970) reported a patient with the Lesch-Nyhan syndrome who showed only a partial deficiency of HGPRTase. More recently, a spectrum of clinical manifestations has been well illustrated by Emmerson and Thompson (1973) who failed to find a significant correlation between clinical severity and enzyme activity in erythrocytes; particularly striking was a completely asymptomatic subject with extremely low levels of HGPRTase activity. Reasons for these discrepancies may include methodological problems in the measurement of very low enzyme activities and the fact that assays of erythrocyte activity may not reflect functional activity in other tissues; thus HGPRTase activity in fibroblasts does not necessarily correspond with that in erythrocytes (Kelley and Meade, 1971). Molecular enzymatic variation between patients with HGPRTase deficiency may be inferred from differences in kinetic properties of the enzyme (Watts, 1974.) A further factor may lie in possible temporal variations, estimations of activity at a late stage of development not necessarily representing the situation at an earlier, critical stage. Arnold and Kelley (1973) have found substantial variability of HGPRTase activity in several patients, including an apparent effect of dietary purines. In this connexion, the neurological behaviour of patient M.B., as stated by his parents, showed a cyclical pattern corresponding to increased output of urinary crystals, though it has not yet been possible to investigate the nature of this association or its relation to HGPRTase activity.

It is conceivable that neurological disorders may be associated with raised erythrocyte APRTase, invariably present in the Lesch-Nyhan syndrome. Benke and Herrick (1972) described a patient with overproduction of uric acid and several features of the Lesch-Nyhan syndrome associated with normal erythrocyte HGPRTase and raised APRTase. Of the patients described by Kelley, Greene, Rosenbloom, Henderson, and Seegmiller (1969), the four with neurological abnormalities had raised levels of APRTase, though they also had very low levels of HGPRTase. Cases with 'partial' deficiency of HGPRTase are usually found to have normal APRTase levels. However, in the present study, raised APRTase levels occurred (G.H. and K.H.) without neurological signs. The varying combinations of reported HGPRTase deficiencies, APRTase activities, and neurological symptoms now seem to rule out the possibility of such a simple connexion between the biochemical and clinical aspects of these disorders.

Studies of family B are consistent with the view that the Lesch-Nyhan syndrome is an X-linked disease transmitted through asymptomatic carrier females (Nyhan and others, 1967), and it is highly probable that the two deceased brothers of M.B. had the Lesch-Nyhan syndrome. The hair follicle studies support this concept, although the frequency of demon- strable HGPRTase-deficient follicles was very low. The follicles were carefully collected, and only those with a complete sheath were analysed. Nevertheless, the mother (N.B.) provided only one follicle clearly deficient in HGPRTase, out of about $\mathbf{4 0}$ analysed. Many follicles showed no APRTase activity, and these provide no information on the presence or absence of an HGPRT-deficient locus.

Studies of the $\mathbf{H}$ family gave similar results. The presence of one or two HGPRTase-deficient follicles in the mother (D.H.) and the sister (P.H.), and the partial erythrocyte HGPRTase deficiency in the sister, are consistent with an X-linked pattern of inheritance. This shows that the studies with hair follicles need to be supported by studies on other cells, e.g. fibroblasts; this will be particularly important in the case of P.H., an otherwise healthy unmarried girl of 21 . In family $\mathrm{H}$ there were indications of disturbances in purine metabolism on the father's side of the family, as evidenced by two subjects with raised plasma uric acid, and a $50 \%$ erythrocyte HGPRTase deficiency in a maternal aunt (V.M.T.): the significance, if any, of this is uncertain.

During the course of these studies it was found that inosine became labelled in erythrocyte HGPRTase assay reaction mixtures. The three substances, hypox anthine, IMP, and inosine, are interconverted is many types of cells by the following pathways:

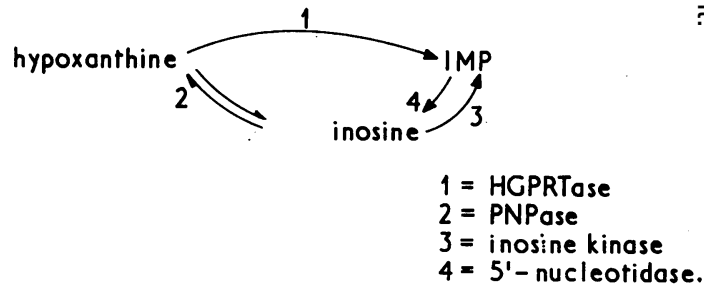

The labelling of inosine from hypoxanthine has recently become of interest in assays of fibroblasts, where it is thought to arise by the sequential action of enzymes 1 and 4 above (Fujimoto and Seegmiller, 1970). However, inosine also becomes labelled in HGPRTase-deficient fibroblasts, even in the presence of thymidine triphosphate (TTP), which inhibits enzyme 4 (Zoref, Sperling, and De Vries, 1974). In our experiments inosine did not arise from IMP, since addition of labelled IMP to reaction mixtures failed to produce labelled inosine. It appears that inosine becomes labelled through an exchange reaction catalysed by enzyme 2 (Kim, Cha, and Parks, 1968)

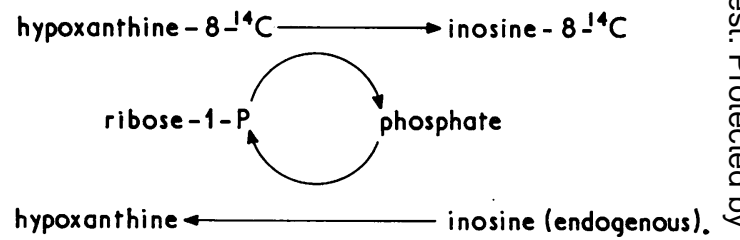


This is consistent with the irregular appearance of labelled inosine, the stimulation of labelling by unlabelled inosine, and by PRPP (which presumably acts as a source of phosphate or of ribose-1phosphate). Evidence for a further conversion of inosine to IMP rests only on the slight stimulation of IMP labelling by inosine and the increase in IMP labelling on storage. Inosine kinase (enzyme 3 ) is believed to be absent from mammalian cells (Friedmann, Seegmiller, and Subak-Sharpe, 1969), but very low activities could assume a greater significance in
HGPRTase assays in cases of severe HGPRTase deficiency. We may be approaching the limit of what can reasonably be inferred from enzyme assays on complex enzyme systems.

We wish to thank Mr. N Phillips for technical assistance during the earlier phases of this work, and Dr. C. Eyre and Professor A. N. Davison for useful discussion. Financial support was provided by the Arthritis and Rheumatism Council for Research, and the Medical Research Council (grant no. G969/470/B).

\section{References}

ARNOLD, W. J., AND KeLLEY, W. N. (1973) 'Hypoxanthine-guanine phosphoribosyltransferase (HGPRT) deficiency: effect of dietary purines on enzyme activity', in 'Advances in Experimental Medicine and Biology, 41 A, Purine metabolism in man: enzymes and metabolic pathways', ed. O. Sperling, A. De Vries, and J. B. Wyngaarden, p. 203. Plenum Press, New York and London

BenKe, P. J., AND HerRICK, N. (1972) Amer. J. Med., 52, 547 (Azaguanine-resistance as a manifestation of a new form of metabolic overproduction of uric acid)

EMmerson, B. T., AND Thompson, C. J. (1973) Quart. J. Med., 42, 423 (The spectrum of hypoxanthine-guanine phosphoribosyltransferase deficiency)

Eyre, C., Davison, A. N., AND ScotT, J. T. (1971) J. Neurol. Neurosurg. Psychiat., 34, 23 (Phosphoribosyl transferase activity in normal subjects, gout patients and children with mental retardation)

Friedmann, T., Seegmiller, J. E., AND Subak-Sharpe, J. H. (1969) Exp. Cell Res., 56, 425 (Evidence against the existence of guanosine and inosine kinases in human fibroblasts in tissue culture)

Fujimoto, W. Y., AND Seegmiller, J. E. (1970) Proc. Nat. Acad. Sci. (U.S.A.), 65, 577 (Hypoxanthine-guanine phosphoribosyl transferase deficiency: activity in normal, mutant and heterozygote-cultured human skin fibroblasts)

Gartler, S. M., Scott, R. C., Goldstein, J. L., Campbell, B., and Sparkes, B. (1971) Science, 172, 572 (LeschNyhan syndrome: rapid detection of heterozygotes by use of hair follicles)

Kelley, W. N., Greene, M. L., Rosenbloom, F. M., Henderson, J. F., and Seegmiller, J. E. (1969) Ann. intern. Med., 70, 155 (Hypoxanthine-guanine phosphoribosyltransferase deficiency in gout)

- , AND MEADE, J. C. (1971) J. biol. Chem., 246, 2953 (Studies on hypoxanthine-guanine phosphoribosyltransferase in fibroblasts from patients with the Lesch-Nyhan syndrome)

- Rosenbloom, F. M., Henderson, J. F., ANd Seegmiller, J. E. (1967) Proc. Nat. Acad. Sci. (U.S.A.), 57, 1735 (A specific enzyme defect in gout associated with the overproduction of uric acid)

Kim, B. K., ChA, S., AND PARKs, R. E. JR. (1968) J. biol. Chem., 243, 1763 (Purine nucleoside phosphorylase from human erythrocytes)

Klinenberg, J. R., Goldfinger, S., Bradley, K. H., and Seegmiller, J. E. (1967) Clin. Chem., 13, 834 (An enzymatic spectrophotometric method for the determination of xanthine and hypoxanthine)

Liddle, L., Seegmiller, J. E., AND LASTER, L. (1959) J. Lab. clin. Med., 54, 903 (The enzymatic spectrophotometric method for determination of uric acid)

Nyhan, W. L., Pesek, J., Sweetman, L., Carpenter, D. G., and Carter, C. H. (1967) Pediat. Res., 1, 5 (Genetics of an X-linked disorder of uric acid metabolism and cerebral function)

Seegmiller, J. E., Rosenbloom, F. M., and Kelley, W. N. (1967) Science, 155, 1682 (Enzyme defect associated with a sex-linked human neurological disorder and excessive purine synthesis)

SORENSEN, L. B. (1970) J. clin. Invest., 49, 968 (Mechanism of excessive purine biosynthesis in hypoxanthine-guanine phosphoribosyltransferase deficiency)

Sperling, O., Frank, M., Ophir, R., Liberman, U. A., Adam, A., and De Vries, A. (1970) Eur. J. clin. biol. Res., 15, 942 (Partial deficiency of hypoxanthine-guanine phosphoribosyltransferase associated with gout and uric acid lithiasis)

WATTS, R. W. E. (1974) J. clin. Path., 27, Suppl. 8, 48 (Molecular variation in relation to purine metabolism)

WyngaARDEN, J. B. (1974) Amer. J. Med., 56, 651 (Metabolic defects of primary hyperuricemia and gout)

Yü, T.-F., Balis, M. E., Krenitsky, T. A., Dancis, J., Silvers, D. N., Elion, G. B., and Gutman, A. B. (1972) Ann. intern. Med., 76, 255 (Rarity of X-linked partial hypoxanthine-guanine phosphoribosyltransferase deficiency in a large gouty population)

Zoref, E., Sperling, O., AND De VRIEs, A. (1974) 'Comment on the assay of purine phosphoribosyltransferases in cultured human fibroblasts', in 'Advances in Experimental Medicine and Biology, 41B, Purine metabolism in man: biochemistry and pharmacology of uric acid metabolism', ed. O. Sperling, A. De Vries, and J. B. Wyngaarden, p. 817. Plenum Press, New York and London 